\title{
COGNITIVE COMPETENCE OF A CHILD IN PRIMARY SCHOOL AGE IN THE CONTEXT OF GROSS MOTOR SKILLS
}

\author{
Ludmila Miklánková \\ Assoc. Prof. Department of Primary and Pre-primary Education, Palacký University in Olomouc, \\ CZECH REPUBLIC, ludmila.miklankova@upol.cz
}

\begin{abstract}
The influence of fine and gross motor development on cognitive abilities continues in both pre-school and younger school age. Complex researches confirm the existence of a positive relationship between the amount of physical activity, cognitive abilities and academic achievement. The spectrum and level of motor skills are positively correlated with cognitive functions and academic achievement, so it is important to focus on developing basic motor skills in children. The aim of the research is to assess the relationship between the level of gross motor skills and the level of cognitive competence in children who undergo the compulsory school attendance. The research was conducted as part of the GF_PdF_2019_0003 project. The research group consisted of 200 primary school aged children - $9.87 \pm 0.65$ year old. The Ethics Committee approval of the author's department was obtained for the research. The participation of the child in the research was completely voluntary, anonymous, free of charge and with the possibility to withdraw from the research anytime. To assess the level of cognitive abilities, a Cognitive Skills Test (TKS) was used to diagnose three areas: verbal, quantitative, and nonverbal skills. The Test of Gross Motor Development-2 was used to diagnose the level of gross motor skills. It is focused on the determination of locomotor and object control skills as components of human's gross motor skills. The correlation of the relationship between cognitive abilities and gross motor levels was evaluated at $p \leq 0.05$. Results revealed that the level of acquired motor skills is very low. It does not meet the requirements determined by curricular documents on primary education in the field of physical education in the Czech Republic. A statistically significant difference in the TGMD-2 test standard score between girls and boys was not found $(p \leq 0.67)$. At the overall level of cognitive abilities, no significant difference $(p \leq 0.061)$ was observed in the studied children in terms of gender. Significant correlation between gross motor skills and cognitive abilities $(p \leq 0.05)$ was confirmed in the given research group in both girls and boys. The relationship between the two variables shows moderate dependence $(r=0.43$; rboys $=0.47$; rgirls $=0.43)$. It is necessary to present the results of the research in the given field in professional journals and to apply it in the practice of primary school teachers.
\end{abstract}

Keywords: gross motor skills, cognitive abilities, elementary school

\section{INTRODUCTION}

According to latest studies, it is evident that cognitive skills are developed and improved in pre-school and adolescent school age (Stöckel a Hughes, 2016; Gwynne a Blick, 2004; Kooistra a kol., 2005; Venetsanou a kol., 2007; Tomporowski Davis, Miller, Naglieri, 2008). The complex relationship between cognitive component and motor development is assessed, nowadays, mainly by foreign researches. The researches confirm the existence of a positive relationship between the amount of physical activity, cognitive abilities and school success (e.g. Röthlisberger et al. 2010, Decker et al. 2011, Howie a Pate 2012). Experts conclude that physical exercise has a positive effect on brain structure and function as well as on the child's 
cognitive abilities (Haapala et al. 2014, Van Dusen et al. 2011). The findings of foreign studies support the claim that the amount and the improvement of motor skills have a significantly positive impact on academic achievement. The level of motor skills positively correlates with cognitive and school success, so it is more than important to focus on developing basic motor skills in children (Huang et al. 2015, Castelli et al. 2007, Kantomaa et al. 2013). Many authors (Adolph \& Berger, 2005; Adolph \& Berger, 2006, Fedewa, 2011 and others) state that there is a close relationship between cognitive development and the volume of acquired motor skills. Grissmer, Grimm, Aiyer, Murrah and Steele (2010) or Tomporowski, Lambourne, and Okumura (2011) caused that the issue of motor skills development is high on the list of scientists' interest. Last mentioned authors found that motor skills are a strong predictor of later success in mathematics and reading. In the Czech Republic, this area is still very little researched (Zikl, Tomášková, Zajíčková, 2013; Zikl, Holoubková, Karásková, Veselíková, 2013). It is necessary to investigate the effects of many parameters (such as type, amount, frequency or timing) of physical activity on cognitive functions. The determination of mechanisms and the long-term impact on the development of the child's motor skills, as well as the transfer of research results into the school environment, needs to be broadened and further studied (Duncan, Dowsett, Claessens,2008; Ericsson et al. 2014, Donelly et al. 2016; Michel, a Roebers, 2008). The results of the research could thus broaden the scope of research in the given field, deepen the knowledge of the importance of developing motor skills for school readiness of the child.

\section{AIM}

The aim of the research is to find out and analyze the relationship between the level of gross motor skills of a compulsory school attendant and the level of his / her cognitive competence. Research questions were addressed within this goal:

1. Which of the monitored cognitive abilities will show a significant difference in comparison with the level of gross motor skills?

2. Will be found gender differences in the level of motor skills and in the level of cognitive abilities of the monitored children?

\section{METHODOLOGY}

The research group consisted of 200 pupils (105 boys, 95 girls) at an average age of $9.87 \pm 0.65$ years attending primary school. None of the children had a handicap. The Ethics Committee of the author's office Faculty of Education, Palacký University in Olomouc, approved the aim and design of the research. For the realization of the research, the approval of the management of primary schools and legal representatives / parents of each child was obtained based on their detailed knowledge of the objectives, methods and implementation of the research. Child participation in research was voluntary and free of charge. During the research, ethical aspects of the research work were followed, children's responses were monitored, and their possible questions to the research were answered. Children could interrupt or leave the testing at any time. The anonymity of acquired data was declared to legal representatives (parents) and school managements. The level of gross motor skills was determined by the Czech version of the standardized Test of Gross Motor Development - 2 (Ulrich, 2000). The test evaluates the basic gross motor skills - locomotor and object control skills. The result is a standard score (gender-based assessment), which is converted to a Gross Motor Development Quotient (GMDQ). It is primarily designed for pre-school children, but is used to determine the level of gross motor skills in older children (Staples \& Reid, 2000; Houwen, Hartman, Jouker, \& Visscher, 2010; Valentini, 2012). The modified version of the Cognitive Abilities Test (Thorndike, Hagen, 1986, revised Czech version Vonkomer, Jílek, 1997) diagnoses three areas of thinking: verbal, quantitative and nonverbal skills. The test monitors the ability of an individual to work with symbols representing words (a verbal component contains 4 subtests), with symbols representing quantities (a quantitative component, contains 3 subtests) and symbols representing spatial, geometric, or pictorial patterns (a non-verbal component contains 3 subtests). The ability to work with these components in their complex relationship can give us an overall picture of the child's cognitive abilities. For the research group was used test variant $C$ for children aged 9.6 to 11.3 years. The achieved gross score (number of correct answers) is converted according to the child's age into the standard age score and the corresponding percentile. The correlation between the level of motor skills and the level of cognitive abilities including individual components (verbal, numerical, nonverbal) was declared with correlation coefficient. The significance level was determined as $p \leq 0.05$. Differences in the level of girls 'and boys' motor skills and the level of their cognitive competences have been identified through the t-test. The data was obtained from the GF_PdF_2019_0003 project.

\section{RESULTS}

The mean value of the standard gross motor skills score was $95.67 \pm 11.17$ (boys $95.34 \pm 13.02$; girls 96.02 
\pm 8.74 ) for the research group, which corresponds to the average level of gross motor skills. In the category very poor and poor, only $9.50 \%$ of probands from the research group were found. There were more boys in this category $(12.4 \%)$ than girls $(6.32 \%)$. Out of the total number of probands, $23 \%$ were below average (out of which was $26.66 \%$ boys and $18.95 \%$ girls). Although the test is not intended to evaluate the performance of children at a given age, the result is surprising because the level of acquired motor skills is very low. It does not meet the requirements determined by curricular documents on primary education in the field of physical education in the Czech Republic. In the average category were $57 \%$ of children based on the results in individual TGMD-2 subtests, but there were more girls $(67.37 \%)$ than boys $(47.62 \%)$. Only a small percentage of children in the research group (3.5\%) reached the level above average (boys $6.66 \%$, girls $7.36 \%)$. In the superior category, only boys (6.66\%) of the total $3.5 \%$ of children are represented (Fig. 1). A statistically significant difference in the TGMD-2 test standard score between girls and boys was not found $(p \leq 0.67)$. On the other hand, some researchers have proven gender differences in their research in both the overall level of gross motor skills and object control skills, where boys reached a higher score (Burns, Brusseau \& Hannon, 2017; Liong, Ridgers \& Barnett, 2015; Slykerman, Ridgers, Stevenson \& Barnett, 2016).

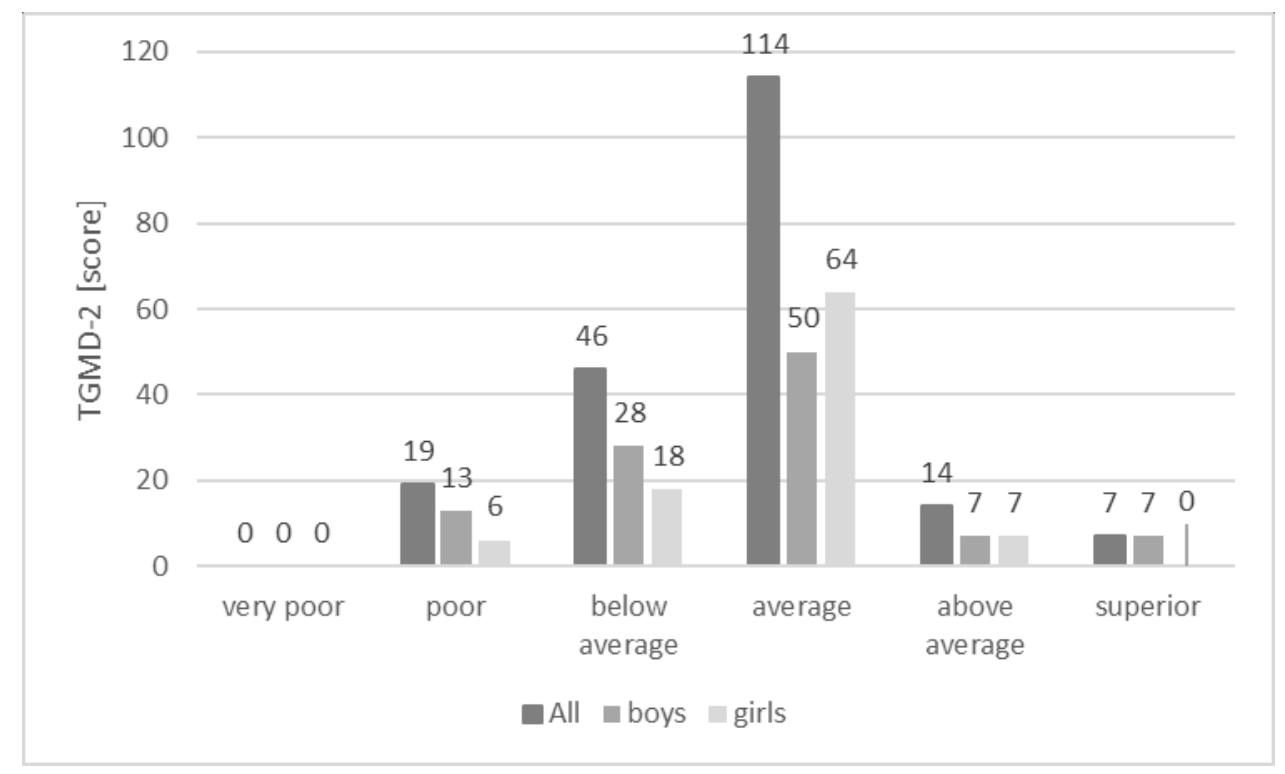

Fig. 1. TGMD-2 score of research group ( $n=200$; boys $=105$, girls=95)

In the field of cognitive abilities, it is common to evaluate verbal, numerical and nonverbal components (Geary \& vanMarle, 2016; Hannula, Räsänen, \& Lehtinen, 2007; Weiland \& Yoshikawa, 2013; Welsh, Pennington, \& Groisser, 1991; Fitzpatrick, McKinnon, Blair \& Willoughby, 2014). In the cognitive test, the average standard score (SVS score) of $101.29 \pm 9.92$ points achieved by the research group corresponds to the overall score of the "average score" (its upper limit). Girls achieved a slightly better score (102.68 \pm 9.13 points) than boys $(99.89 \pm 10.71$ points). In the subtest evaluating the verbal component, the girls (103.95 \pm $11.04)$ and boys $(102.75 \pm 10.99)$ achieved approximately the same score, which is rated as average. The overall results correspond to the researches of other authors who confirm only little (not significant) differences between girls and boys, men and women in these skills (Hyde, Lindberg, Linn, Ellis, \& Wil-liams, 2008; Lindberg, Hyde, Petersen, \& Linn, 2010). Washington, Branum-Martin, Lee-James \& Sun (2019) also note the absence of gender differences in the language component for the same age group, but point to the differences found among girls and boys in reading skills. The average level (101.64 \pm 12.43$)$ was also found in the area of numerical skills (quantitative component), where girls obtained a score of $104.51 \pm 12.97$ and boys $98.77 \pm 12.09$ (Fig. 2). In assessing the significance of the difference in individual components of cognitive abilities in terms of gender, there was a significant difference in the quantitative component ( $p \leq 0.003)$ where girls achived better results. Currently, in many countries (as in the Czech Republic) there is a decrease of interest in mathematics and technical sciences (Eccles \& Wang, 2016; Shapiro \& Williams, 2012), but these are not limited to basic numerical work, but they are also related to the development of logical thinking of children. Another subtest of the cognitive test includes a non-verbal component focused on the ability to work with symbols / images and their spatial arrangement. The score in this part of the test is generally lower in the research group than in the verbal and quantitative component (girls $99.59 \pm 12.31$, boys $98.16 \pm 12.34$ ), but is still rated as the average score. At the overall level of cognitive abilities, no significant difference ( $p \leq 0.061)$ was observed in the studied children in terms of gender (Fig. 2). But Halpern, Benbow, Geary, Gur, Hyde, \& Gernsbacher (2007) or Levine, Foley, Lourenco, Ehrlich, and Ratliff (2016) 
have found gender differences in spatial processing, where boys performed better than girls. They conclude that boys in this area rely more on spatial approaches or strategies.

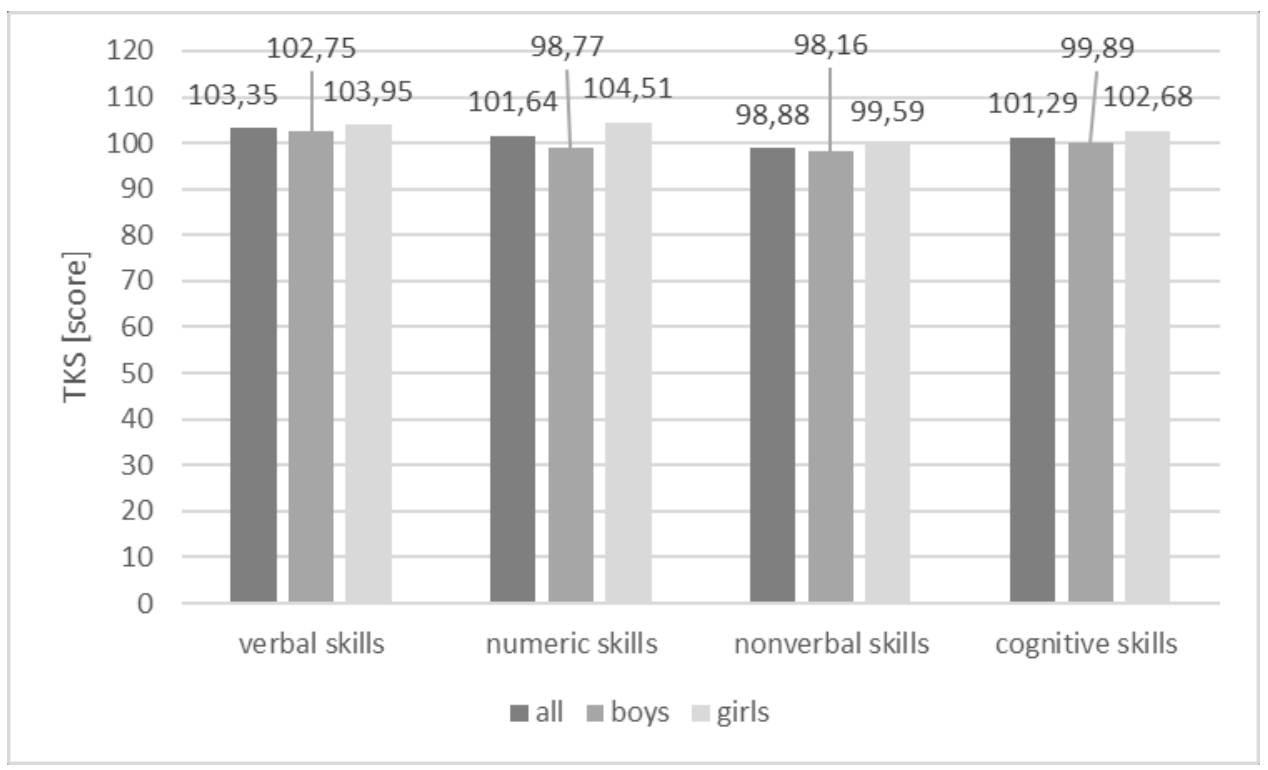

Fig. 2. Test Cognitive Abilities Test score of research group (TKS) $(n=200$; boys $=105$, girls=95)

In the application of mentioned research methods, a significant correlation between gross motor skills and cognitive abilities $(p \leq 0.05)$ was confirmed in the given research group in both girls and boys. The relationship between the two variables shows moderate dependence $(r=0.43$; rboys $=0.47$; rgirls $=0.43)$. The level of motor skills correlate with the verbal component at the level of moderate dependence $(r=0,55$, rboys $=0,61$, rgirls $=0,44$ ). Motor skills with the quantitative component correlate at the low level $r=0,30$ (girls rgirls $=0,32$, rboys $=0,36$ ). Interestingly, the fact that in girls the correlation of motor skills and non-verbal components of the low level (rgirls $=0,30$ ). In boys, the correlation between the monitored variables is higher than in girls (rboys $=0,34)$. The results of the research group are significant $(p \leq 0,05)$ and confirm the importance of the development of child's motor skills for its cognitive development. Van der Fels, Te Wierike, Hartman, Elferink-Gemser, Smith, \& Visscher (2015), in their research on the issue of the relationship between motor skills and cognitive abilities of children, also noted that current research in the field presents this relationship as weak to strong therefore it is not yet clear. Nevertheless, they confirm a stronger relationship between the basic categories of motor and cognitive skills, especially in children under 13 years of age. Here we see the importance of the role of a primary school teacher, who may have the opportunity to positively influence the pupil's cognitive development through the development of motor skills. Some authors point out the inadequate work of primary school teachers who do not encourage pupils' interest in, for example, mathematics and technical sciences (Cimpian et al., 2016; Riegle-Crumb a Humphries, 2012). Higashionna et al. (2017) emphasize that it is necessary to identify precisely the possibilities for interventions that would help solve the problems of motor coordination and related cognitive abilities in children.

\section{CONCLUSIONS}

A significant relationship between gross motor skills and cognitive abilities $(p \leq 0.05)$ was found in the research in both girls and boys. Correlation is at the level of low to moderate dependence. Partial research in this area has certain limits, such as the low number of probands in research groups, the diversity of methods used in individual countries (especially in cognitive skills) and thus the difficult comparison of results at international level. The level of cognitive abilities is also influenced by the quality of curricular documents of schools involved in research (the quality of school curricula), as well as by the level of professional competencies of teachers in these schools. Nevertheless, it is necessary to further and very carefully examine the area and discuss the results as widely as possible in scientific forums and conferences. Positive discovery of the relationship between child's level of motor skills and cognitive abilities would support the idea of early childhood intervention by educators in the youngest age groups, where these interventions can be highly effective. 


\section{REFERENCE LIST}

Adolph, K. E. and Berger, S. E. (2006). Motor development. In D. Kuhn and R. S. Siegel (Eds.), Handbook of child psychology: Vol. 2: Cognition, perception and language (6th ed.), 161-213. New York: Wiley.

Adolph, K. E., and Berger, S. E. (2005). Physical and motor development. In M. H. Bornstein a M. E. Lamb (Eds.) Developmental science: An advanced textbook (5th ed.), 223-281. Mahwah, NJ: Erlbaum.

Burns, R. D., Brusseau, T. A. and Hannon, J. C. (2017). Multivariate association among health-related fitness, physical aktivity and TGMD-3 test items in disadvantaged children from low-income families. Perceptual and Motor Skills, 124 (1), 86-104.

Castelli, D. M., Hillman, Ch., Buck, S. M. and Erwin, H. E. (2007). Physical fitness and academic achievement in third-and fifth-gradestudents. J Sport Exerc Psychol., 29 (2), 239-52.

Cimpian, J. R., Lubienski, S. T., Timmer, J. D., Makowski,M. B. and Miller, E. K. (2016). Have gender gaps in math closed? Achievement, teacher perceptions, and student behaviors across two ECLS-K cohorts. AERA Open, 2. https://doi.org/10.1177/2332858415616358

Decker, S. L., Englund, J. A., Carboni, J. A. and Brooks, J. H. (2011). Cognitive and developmental influences in visual-motor integration skills in young children. Psychological Assessment, 23 (4), 1010-1016. http://dx.doi.org/10.1037/a0024079

Donnelly, J. E.; Hillman, Charles H.; Castelli, D., Etnier, J. L., Lee, S., Tomporowski, P., Lambourne, K. and Szabo-reed, A. N. (2016). Physical Activity, Fitness, Cognitive Function, and Academic Achievement in Children: A Systematic Review. Med Sci Sports Exerc, 48 (6), 1197-1222. doi:10.1249/MSS.0000000000000901.

Duncan, G. J., Dowsett, C. J., Claessens, A., Magnuson, K., Huston, A. C., Klebanov, P. et al. (2007). School readiness and later achievement. Developmental Psychology, 43, 1428-1446.

Eccles, J. S. and Wang, M. T. (2016). What motivates female sand males to pursue careers in mathematics and science? International Journal of Behavioral Development, 40, 100-106. https://doi.org/10.1177/0165025415616201

Ericsson, I. and Karlsson, M. K. (2014). Motor skills and school performance in children with daily physical education in schoola 9-year intervention study. Scand. J. Med. Sci. Sports 24 (2), 273-278. doi: 10.1111/j. 1600-0838.2012.01458.xPMID:22487170. 12

Fedewa, A. L. and Ahn, S. (2011). The effects of physical activity and physical fitness on children's achievement and cognitive outcomes: a meta-analysis. Res. Q. Exerc. Sport, 82, 521-535.

van der Fels, I. M., Te Wierike, S.C., Hartman, E., Elferink-Gemser, M.T., Smith, J. and Visscher C. (2015). The relationship between motor skills and cognitive skills in 4-16 year old typically developing children: A systematic review. J. Sci. Med. Sport. 18 (6), 697-703. doi: 10.1016/j.jsams.2014.09.007

Fitzpatrick, C., McKinnona, R. D., Blair, C. B. and Willoughbyb, M. T. (2014). Do preschool executive function skills explain the school readiness gap between advantaged and disadvantaged children? Learning and Instruction, 30 (April 2014), 25-31.

Geary, D. C. van Marle, K. (2016). Young children's core symbolic and nonsymbolic quantitative knowledge in the prediction of later mathematics achievement. Developmental Psychology, 52 (12), 2130-2144.

Grissmer, D., Grimm, K. J., Aiyer, S. M., Murrah, W. M. and Steele, J. S. (2010). Fine motor skills and Early understanding of the world: two new school readiness indicators. Developmental Psychology, [online]. 46 (5), 1008-1017 [cit. 2019-05-20]. doi: 10.1037/a0020104. ISSN 1939-0599.

Gwynne, K. and Blick, B. A. (2004). Motor Performance Checklist for 5-year-olds: A tool for identifying children at risk of developmental co-ordination disorder. Journal of Paediatrics and Child Health, 40 (7), 369-373 [cit. 2019-05-15]. DOI: 10.1111/j.1440-1754.2004.00404.x. ISSN 1034-4810. http://doi.wiley.com/10.1111/j.1440-1754.2004.00404.x.

Haapala, E. A., Poikkeus, A. M., Tompuri, T., Kukkonen-Harjula, K., Leppanen, P. H., Lindi, V. and Lakka, T. A. (2014). Associations of motor and cardiovascular performance with academic skills in children. Med Sci Sports Exerc., 46 (5), 1016-1024. doi:10.1249/MSS.0000000000000186PMID:24126966.

Halpern, D. F., Benbow, C. P., Geary, D. C., Gur, R. C.,Hyde, J. S. and Gernsbacher, M. A. (2007). The science ofgender differences in science and mathematics. Psycho-logical Science in the Public Interest, 8, 1-51. https://doi.org/10.1111/j.1529-1006.2007.00032.x 
Hannula, M. M., Räsänen, P. and Lehtinen, E. (2007). Development of Counting Skills: Role of Spontaneous Focusing on Numerosity and Subitizing-Based Enumeration. Mathematical Thinking and Learning, 9 (1), 51-57.

Higashionna, T., Iwanaga,R., Tokunaga, A., Nakai, A., Tanaka, K., Nakane, H. and Tanaka, G. (2017). Relationship between Motor Coordination, Cognitive Abilities, and Academic Achievement in Japanese Children with Neurodevelopmental Disorders. Hong Kong J Occup Ther, 30 (1): 49-55. doi: 10.1016/j.hkjot.2017.10.002

Houwen, S., Hartman, E. and Jonker, L. (2010). Reliability and validity of the TGMD-2 in primary-school-age children with visual impairments. Adapted Physical Activity Quarterly 27, 149-159.

Howie, E. K. and Pate, R. R.. (2012). Physical activity and academic achievement in children: A historical perspective. Journal of Sport and Health Science, 1 (3), 160-169. doi: 10.1016/j.jshs.2012.09.003. ISSN 20952546. http://linkinghub.elsevier.com/retrieve/pii/S2095254612000737

Huang, T., Tarp, J., Domazet, S. L., Thorsen, A.K., Froberg, K. and Andersen, L. B. (Ed.) (2015). Associations of Adiposity and Aerobic Fitness with Executive Function and Math Performance in Danish Adolescents. J. Pediatr. 167 (4), 810-815. doi:10.1016/j.jpeds.2015.07.009PMID:26256018

Hyde, J. S., Lindberg, S. M., Linn, M. C., Ellis, A. B. and Williams, C. C. (2008). Gender similarities characterize math performance. Science, 321, 494-495. https://doi.org/10.1126/science.1160364

Kantomaa, M. T., STamatakis, E., Kankaanpaa, A., Kaakinen, M., Rodriguez, A. and Taanila, A. (Ed.) (2013). Physical activity and obesity mediate the association between childhood motor function and adolescents' academic achievement. Proc Natl Acad Sci USA 110 (5), 1917-1922 doi:10.1073/pnas.1214574110PMID:23277558;PubMedCentralPMCID: PMC3562837.

Kooistra, L., Crawford, S., Dewey, D., Cantell, M., Levine, S. C., Foley, A., Lourenco, S., Ehrlich, S. and Ratliff, K. (2016). Gender differences in spatial cognition:Advancing the conversation. Wiley Interdisciplinary Reviews: Cognitive Science,7, 127-155.

Lindberg, S. M., Hyde, J. S., Petersen, J. L. and Linn, M. C. (2010). New trends in gender and mathematics perfor-mance: A meta-analysis. Psychological Bulletin,136, 1123. https://doi.org/10.1037/a0021276

Liong, G. H., Ridgers, N. D. and Barnett, L.M. (2015). Association between skill perceptions and young children's actual fundamental movement skills. Perceptual and Motor Skills, 120 (2), 591-603.

Michel, E. and Roebers, C., M. (2008). Children in Regular and Special Needs Classes: Cognitive and NonCognitive Aspects. Swiss Journal of Psychology, 67 (4), 249-259. http://econtent.hogrefe.com /doi/ abs/10.1024/1421-0185.67.4.249

Riegle-Crumb, C. and Humphries, M. (2012). Exploringbias in math teachers'perceptions of students'ability by gender and race/ethnicity. Gender and Society, 26, 290-322.

https://doi.org/10.1177/089124321143461

Röthlisberger, M., Neuenschwander, R., Michel, E. and Roebers, C. M. (2010). Exekutive Funktionen: Zugrundeliegende kognitive Prozesse und deren Korrelate bei Kindern im späten Vorschulalter. Zeitschrift für Entwicklungspsychologie und Pädagogische Psychologie, 42 (2), 99-110 doi: 10.1026/0049-8637/a000010. ISSN 0049-8637. http://econtent.hogrefe.com/doi/abs/10.1026/0049$8637 / \mathrm{a} 000010$

Slykerman, S., Ridgers, N. D., Stevenson, C. and Barnett, L. M. (2016).How important is yoiung children's actual and perceived movement skill competence to their physical activity? Journal of Science and Medicine in Sport, 19 (6), 488-492.

Stöckel, T. and Hughes, C. M. L. (2016). The relation between measures of cognitive and motor functioning in 5- to 6-year old children. Psychological Research, 80 (4), 543-554. doi: 10.1007/s00426-015-06620

Thorndike, R. L. and Hagen, E. (1998). Test kognitivních schopností. Translation and editing J. Vonkomer a J. Jílek. Psychodiagnostika. Brno: Bratislava, 1998.

Tomporowski, P. D., Lambourne, K., and Okumura, M. S. (2011). Physical activity interventions and children's mental function: An introduction and overview. Preventive Medicine, 52, S3-S9. doi: 10.1016/j.ypmed.2011.01.028. ISSN 00917435. http://linkinghub.elsevier. com/retrieve/pii/ S00917 43511000569 
Tomporowski, P. D., Davis, C. L., Miller, P. H. and Naglieri, J. A. (2008). Exercise and Children's Intelligence, Cognition, and Academic Achievement. Educational Psychology Review [online]. 20 (2), 111-131. doi: 10.1007/s10648-007-9057-0. ISSN 1040-726x. http://link.springer.com/10.1007/s 10648-007-9057-0

Ulrich, D. (2000). A. Test of gross motor development: examiner's manual. 2. vyd. Austin: Pro-Ed publisher, $1-60$.

Valentini, N. C. (2012). Validity and Reliability of the TGMD-2 for Brazilian Children. Journal of Motor Behavior, 44 (4), 275-280.

Van dusen, D. P., Kelder, S. H., Kohl, H.W., Ranjit, N. and Perry, Ch. L. (2011). Associations of Physical Fitness and Academic Performance Among School children. J. Sch. Health, 81 (12), 733-740. doi:10.1111/J.17461561.2011.00652.XPMID:WOS:000297242500002. 11.

Venetsanou, F., K., Aggeloussis, N., Serbezis, V. and Taxildaris, K. (2007). Use of the Bruininks-Oseretsky Test of Motor Proficiency for identifying children with motor impairment. Developmental Medicine and Child Neurology, 49 (11), 846-848. doi: 10.1111/j.1469-8749.2007.00846.x. http://doi.wiley.com/10.1111/j.1469-8749.2007.00846.x.

Washington, J. A., Branum-Martin, L., Lee-James, R. and Sun, C. (2019). Reading and Language Performance of Low-Income, African American Boys in Grades 1-5. Reading and Writing Quarterly, 35 (1), 42-64. doi: 10.1080/10573569.2018.1535777

Weiland, Ch. and Yoshikawa, H. (2013). Impacts of a Prekindergarten Program on Children's Mathematics, Language, Literacy, Executive Function, and Emotional Skills. Child Development, 84 (6), 2112-2130.

Welsh, M. C., Pennington, B. F. and Groisser, D. B. (1991) A normative-developmental study of executive function: A window on prefrontal function in children. Developmental Neuropsychology, 7 (2), $131-$ 149. doi: $10.1080 / 87565649109540483$

Zikl, P., Holoubková, N., Karásková, H. and Veselíková, T. B. (2013). Gross Motor Skills of Children with Mild Intellectual Disabilities. International Journal of Social, Behavioral, Educational, Economic, Business and Industrial Engineering, 7 (10), 2789-2795. https://www.scribd.com/document/341632012/GrossMotor-Skills-of-Children-with-Mild-Intellectual-Disabilities-pdf

Zikl, P., Tomášková, M. and Zajičková, B. (2012). Functional motor abilities of the upper extremities in children with mild intellectual disabilities. In Education and educational psychology (EDU 2012): 3rd international conference. Istanbul: Cognitive Counselling and Conference Services (C-crcs), ISSN 1986-3020. 